\title{
Salvianolic acid B protects against acute and chronic liver injury by inhibiting Smad2C/L phosphorylation
}

\author{
XIANG-MING TAO, DONG LI, CHONG ZHANG, GUANG-HUA WEN, CHAO WU, \\ YUAN-YUAN XU, YUE KAN, WAN-PENG LU, HAN-YAN DING and YAN YANG \\ Department of Pharmacology, Anhui Medical University, Key Laboratory of Anti-inflammatory \\ and Immunopharmacology, Ministry of Education, Hefei, Anhui 230032, P.R. China
}

Received May 3, 2019; Accepted March 19, 2020

DOI: $10.3892 /$ etm.2021.9772

\begin{abstract}
Salvianolic acid B (Sal B) has strong antioxidant and anti-fibrosis effects, which are related to the transforming growth factor $\beta /$ Smad signaling pathway. However, how Sal B affects this antioxidant pathway and the phosphorylation (p-) of Smad2 at both the COOH-terminal (pSmad2C) and linker region (pSmad2L) are unknown. The aims of the present study were to investigate the underlying mechanisms of Sal B on acute and chronic liver injury induced by $\mathrm{CCl}_{4}$ and $\mathrm{H}_{2} \mathrm{O}_{2}$, and its effects on $\mathrm{p}-\mathrm{Smad} 2 \mathrm{C} / \mathrm{L}$. In in vivo experiments, acute and chronic liver injury models were induced by $\mathrm{CCl}_{4}$, and the oxidative damage cell model was established in vitro with $\mathrm{H}_{2} \mathrm{O}_{2}$. Liver histopathology was assessed using hematoxylin and eosin and Van Gieson's staining. Moreover, serum biochemical indicators were analyzed using specific assay kits. Furthermore, the present study evaluated the oxidant/antioxidant status in acute and chronic liver injury models by oxidative stress parameters such as malondialdehyde, glutathione and superoxide dismutase. In addition, western blot analysis was performed to analyze the protein expression levels of pSmad2C, pSmad2L, nuclear factor erythroid-2-related factor 2 (Nrf2) and heme oxygenase-1 (HO-1). It was found that Sal B improved liver histology, decreased the levels of aminotransferase and attenuated oxidative stress in acute and chronic liver injury models. Additionally, the protein expression levels of pSmad2C and pSmad2L were decreased, but Nrf2 and HO-1 expression levels were increased both in vivo and in vitro. Collectively, the present results suggested that Sal B may protect against acute and chronic liver injury via
\end{abstract}

Correspondence to: Professor Yan Yang, Department of Pharmacology, Anhui Medical University, Key Laboratory of Antiinflammatory and Immunopharmacology, Ministry of Education, 81 Meishan Road, Hefei, Anhui 230032, P.R. China

E-mail: yangyan@ahmu.edu.cn

Key words: salvianolic acid B, phosphorylated Smad2 at $\mathrm{COOH}-$ terminal/linker region, nuclear factor erythroid-2-related factor 2/ heme oxygenase-1, liver injury inhibition of Smad2C/L phosphorylation, and the Nrf2/HO-1 signaling pathway may play an important role in this process.

\section{Introduction}

Acute liver injury represents a stage of sudden deterioration of liver function that is characterized by cell necrosis, inflammation and oxidative damage (1). Hepatic fibrosis refers to the excessive deposition of diffuse extracellular matrix (ECM) in liver tissue, which is the repair response in organisms to chronic liver injury (2). The accumulation of ECM results in hepatic fibrosis and hepatocellular carcinoma, and can increase the mortality rate of liver diseases (3). Thus, ECM has direct clinical implications to treat and mitigate acute and chronic liver injury. Transforming growth factor- $\beta 1$ (TGF- $\beta 1$ ) is the most effective activator of hepatic stellate cells (HSC) in liver fibrosis, acting via the Smads pathway (4). Different measures to block and/or regulate TGF- $\beta /$ Smad signal transmission may be an important strategy to prevent hepatic fibrosis (5). The Smads family have three functional domains, N-terminal Mad homology 1, C-terminal Mad homology 2 and intermediate linker region (6). Phosphorylated (p)Smads at the $\mathrm{COOH}-$ terminal or linker region form different complexes with Smad4, which then translocate to the nucleus (6). In acute liver injury, TGF- $\beta 1$ and platelet-derived growth factor synergistically activate $\mathrm{pSmad} 2 \mathrm{C} / \mathrm{L}$ and promote collagen synthesis in activated HSC (7). Furthermore, during chronic liver disease progression, fibrogenic $\mathrm{pSmad} 2 \mathrm{C} / \mathrm{L}$ signaling was affected by TGF- $\beta 1$, which accelerates liver fibrosis (8). Moreover, it was reported that a crosstalk between the nuclear factor erythroid2-related factor 2 (Nrf2) and TGF- $\beta 1$ pathways promotes the development of hepatocellular carcinoma (9). Previous studies have shown that Nrf 2 negatively acts against fibrotic TGF- $\beta 1$ signaling (10), and that TGF- $\beta 1$ promotes the generation of reactive oxygen species (ROS) by inhibiting Nrf2 and its target antioxidant enzymes, such as heme oxygenase-1 (HO-1) and $\mathrm{NAD}(\mathrm{P}) \mathrm{H}$ dehydrogenase (quinone) 1 , during hepatic fibrosis (11). Furthermore, the TGF- $\beta /$ Smad signaling pathway also induces activating transcription factor 3 (ATF3), which in turn complexes with Nrf2 to suppress Nrf2 target gene expression (12).

Salvianolic acid B (Sal B) is extracted from the root and rhizome of Salvia miltiorrhiza, which has antioxidative and 
antifibrosis effects (13). In vivo experimentation has shown that Sal B enhances the ability of antioxidant in liver injury, eliminates ROS and inhibits the activation of HSC (14). In in vitro experiments, Sal B treatment could downregulate the expression of $\alpha$-SMA and collagen type I in TGF- $\beta 1$-induced HSC (15). The authors' previous study found that Sal B exerts antihepatic fibrosis effects via modulation of $\mathrm{pSmad} 3 \mathrm{C} / \mathrm{L}$ (16). However, it is not fully understood how Sal B affects $\mathrm{pSmad} 2 \mathrm{C} / \mathrm{L}$ in acute and chronic liver injury, nor its effect on the antioxidant pathway.

The aim of the present study was to investigate the protective effect of Sal B in $\mathrm{CCl}_{4}$ - and $\mathrm{H}_{2} \mathrm{O}_{2}$-induced acute and chronic liver injury, and to identify the possible underlying mechanisms. The present study also assessed the effect of pSmad2C, pSmad2L and the Nrf2/HO-1 pathway on liver injury pathogenesis.

\section{Materials and methods}

Chemicals. Sal B (cat. no. PS12091001; purity $\geq 95 \%$ ) was obtained from Chengdu Push Bio-Technology Co., Ltd; Bio-Equiop. Sal B was initially separated and refined from the dried roots of Salvia miltiorrhiza. $\mathrm{CCl}_{4}$ (purity $\geq 99.5 \%$; concentration, $10.4 \mathrm{~mol} / \mathrm{l}$ ), obtained from Shanghai Puyi Chemical Reagent Co., Ltd. Commercial kits were used to determine the levels of malondialdehyde (MDA; cat. no. A003-1-2), glutathione (GSH; cat. no. A005-1-2) and superoxide dismutase (SOD; cat. no. A001-1-2) were purchased from Jianchen Institute of Biotechnology. Immunostaining StreptavidinPeroxidase (SP) kit (cat. no. SP9001) was obtained from OriGene Technologies, Inc.

Animals and experimental groups. A total of 60 Kunming male mice (weight 18-22 kg; age 6-8 weeks) were purchased from Animal Center of Anhui Medical University (Anhui, China). All mice were maintained in a $12 \mathrm{~h} \mathrm{light/dark} \mathrm{alter-}$ nating cycle at a room temperature $\left(23 \pm 2^{\circ} \mathrm{C}\right)$ with a humidity of $50 \pm 10 \%$. The experiment was carried out after 1 week of adaptive feeding. In both the acute and chronic liver injury experiments, mice were randomized into five groups: Control group (Control), model group (Model), $\mathrm{CCl}_{4}+\mathrm{Sal} \mathrm{B} 7.5$ group (Sal B 7.5), $\mathrm{CCl}_{4}+\mathrm{Sal} \mathrm{B} 15$ group (Sal B 15) and $\mathrm{CCl}_{4}+\mathrm{Sal}$ B 30 group (Sal B 30) ( $\mathrm{n}=6$ in each group). All mice were allowed free access to food and water. In the acute liver injury experiment, mice in the control and model group were given $0.9 \%$ saline daily, and the three Sal B groups were given Sal B $(7.5,15$ and $30 \mathrm{mg} / \mathrm{kg}$, respectively) daily by intragastric administration, for a duration of 1 week. Then, $24 \mathrm{~h}$ after the final dose of Sal B, the control group mice were given olive oil and the other groups received $0.1 \% \mathrm{CCl}_{4}$ (dissolved in olive oil) via single intraperitoneal injection $(10 \mathrm{ml} / \mathrm{kg})(17)$. In the chronic liver injury experiment, mice in the control and model group were given $0.9 \%$ saline daily, and the three Sal B groups were given Sal B (7.5, 15 and $30 \mathrm{mg} / \mathrm{kg}$, respectively) daily by intragastric administration for 8 weeks. Control mice received olive oil and Sal B groups received $20 \% \mathrm{CCl}_{4}$ (dissolved in olive oil) by intraperitoneal injection $(1 \mathrm{ml} / \mathrm{kg} / 2$ weeks) for 8 weeks $(18,19)$. Then, $24 \mathrm{~h}$ after the last intraperitoneal injection of $\mathrm{CCl}_{4}$, all mice were anesthetized in a chamber with $1.4 \%$ isoflurane and $100 \%$ oxygen for $2 \mathrm{~h}$. After retro-orbital collection of blood under anesthesia, the mice were transferred to a face mask providing 5\% isoflurane. Mice were placed in sternal recumbency and a surgical level of anesthesia was assessed by firm bilateral foot pinch. When each mouse was fully anesthetized, euthanasia was performed using cervical dislocation. Subsequently, the liver of the mice was harvested.

All the experiments were conducted in accordance with the guidelines for Ethical Review of laboratory animal welfare in the Animal Center of Anhui Medical University. The animal experiments were approved by the Experimental Animal Ethics Committee of Anhui Medical University.

Cell culture and Sal B treatment. Rat hepatic stellate cells HSC-T6 were purchased from Nanjing KeyGen Biotech. Co. Ltd. HSC-T6 cells were incubated in 6 well plates $\left(2 \times 10^{5}\right.$ cells/ well) for $24 \mathrm{~h}$ at $37^{\circ} \mathrm{C}$ in $5 \% \mathrm{CO}_{2}$ with DMEM (Gibco; Thermo Fisher Scientific, Inc.) supplemented with 10\% FBS (Zhejiang Tianhang Biotechnology Co., Ltd.). Cells were treated with various final concentrations of Sal B (25, 50 and $100 \mu \mathrm{mol} / \mathrm{l})$. Then, $100 \mu \mathrm{M} \mathrm{H}_{2} \mathrm{O}_{2}$ (Nanjing KeyGen Biotech Co., Ltd.) was added to each well and incubated at $37^{\circ} \mathrm{C}$ for $6 \mathrm{~h}$. The control group was treated a same volume of medium $(20,21)$.

Biochemical index assay. Liver function is an index reflecting the liver physiological status. Moreover serological alanine transaminase (ALT) and aspartate aminotransferase (AST) are classical indicators which were used to test liver function. A total of $\sim 1 \mathrm{ml}$ blood sample were obtained prior to euthanizing the mice, for determination of serum enzymes levels. ALT (cat. no. C009-2-1) and AST (cat. no. C010-2-1) levels were determined using commercial reagent kits (Nanjing Jiancheng Bioengineering Institute) with an automatic biochemical analyzer following the manufacturer's protocols.

Hematoxylin and eosin (HE), and Van Gieson's (VG) staining. Fresh liver tissues were sliced into applicable sections $(5-10 \mathrm{~mm})$, then fixed in $4 \%$ buffered paraformaldehyde at room temperature for 1 week, dehydrated and embedded in paraffin. These were then sectioned at $5 \mu \mathrm{m}$ and stained with hematoxylin $(0.2 \%, 15 \mathrm{~min})$ and eosin $(5 \%, 1 \mathrm{~min})$ for histopathological analyses. VG staining (1.2\% picric acid and $1 \%$ poinsettia, $1 \mathrm{~min}$ ) method was used to detect collagen fibers at room temperature. Sections stained with HE (magnification, $\mathrm{x} 400$ ) and VG (magnification, $\mathrm{x} 100$ ) were photographed under a light microscope (Nikon 80i; Nikon Corporation). The quantitative assessment of fibrotic changes in the liver tissues was evaluated by HPIAS-1000 auto Medical Image Analyzing system.

Assay of oxidative biochemical parameters. Fresh liver tissue from each group $(n=6)$ was cleaned with saline solution. Tissues were grinded into $10 \%$ tissue homogenate, then centrifuged for $10 \mathrm{~min}$ at $4{ }^{\circ} \mathrm{C}$ and $1,509.3 \mathrm{x} \mathrm{g}$, to obtain the superntant. Subsequently, activities of SOD and the contents of MDA and GSH in liver tissues were detected using commercially kits according to the manufacturer's protocol (I). SOD activity was determined by the hydroxylamine method, in which the $\mathrm{O}_{2}$ - anions oxidize hydroxylamine to the sulfite form, generating a purple-red color with a color-developing agent. SOD removes the $\mathrm{O}_{2}$-anions, which reduces sulfite 
formation and the absorbance values can be used to quantify SOD activity. In total, $10 \mu$ liver tissue supernatant was added to hydroxylamine hydrochloride buffer, xanthine and xanthine oxidase, mixed and incubated at $37^{\circ} \mathrm{C}$ for $40 \mathrm{~min}$. Then, the chromogenic agent was added. The optical density (OD) value of each group of the sample was measured at a wavelength of $550 \mathrm{~nm}$ after zero correction with distilled water, a standard curve was drawn and the activity value of SOD was calculated. (II) GSH reduces 5-dithio-2-nitrobenzoic acid (DTNB) to 2-nitro-5-mercaptobenzoic acid, which is yellow in an acidic environment and can be quantified at $412 \mathrm{~nm}$; the measured value is proportional to glutathione content. In total, $100 \mu \mathrm{l}$ liver tissue supernatant was added to phosphate buffer containing $500 \mathrm{mM}$ DTNB. After $5 \mathrm{~min}$, the color turned yellow and OD values of each group were measured at $405 \mathrm{~nm}$ after zero correction. Standard curves were established and glutathione levels in the samples were calculated. (III) MDA concentration was determined by measuring the concentration of thiobarbituric acid (TBA) reactive substances. Firstly, $100 \mu$ l liver tissue supernatant was added in $4 \mathrm{ml} 0.6 \%$ TBA solution. The mixture was reacted in boiling water bath $\left(100^{\circ} \mathrm{C}\right)$ for $15 \mathrm{~min}$, then centrifuged for $10 \mathrm{~min}$ at $1,509.3 \mathrm{x} \mathrm{g}$ and $25^{\circ} \mathrm{C}$ after cooling and the supernatant was collected. The $\mathrm{OD}$ values of each group were measured at a wavelength of $532 \mathrm{~nm}$, zero correction was performed used distilled water. (IV) Coomassie Brilliant Blue can be used to determine protein content at $25^{\circ} \mathrm{C}$. The dye combines with the protein, forming a cyan protein-pigment conjugate, with maximum light absorption at $595 \mathrm{~nm}$. The light absorption value is proportional to the protein content. The supernatant of 0.05 tissue homogenate was mixed with $1 \mathrm{ml}$ Coomassie brilliant blue solution. After $10 \mathrm{~min}$, the OD value of each tube was measured at a wavelength of $595 \mathrm{~nm}$ with a $1 \mathrm{~cm}$ light path.

Immunohistochemical analysis. Paraffin sections were deparaffinized in xylene and rehydrated in different concentrations of ethanol (100, 90, 80 and 70\%). Non enzymatic antigen retrieval was processed by heating the $4 \mu \mathrm{m}$ sections to $121^{\circ} \mathrm{C}$ in $0.01 \mathrm{M}$ sodium citrate buffer ( $\mathrm{pH} \mathrm{6.0)}$ for $10 \mathrm{~min}$. Then, the sections were cooled, rinsed in TBST $(0.1 \%$ Tween-20) and incubated in methanol with $3 \% \mathrm{H}_{2} \mathrm{O}_{2}$ for 30 min at $37^{\circ} \mathrm{C}$ to restrain endogenous peroxidase activity. After rinsing three times, the sections were blocked with $5 \%$ BSA at $37^{\circ} \mathrm{C}$ for $30 \mathrm{~min}$, then incubated with rabbit anti $\operatorname{Nrf} 2$ (1:3,000; cat. no. ab137550; Abcam) for $1 \mathrm{~h}$ at room temperature in a humid chamber. Liver sections were then rinsed in TBST and incubated with horseradish peroxidase-labeled goat anti rabbit IgG polymer (1:3,000; cat. no. ab137550; Abcam) at $37^{\circ} \mathrm{C}$ for $1 \mathrm{~h}$. The results of Nrf2 expression levels in liver tissues were evaluated using a semi quantitative technique. At the same light intensity and magnification, $\mathrm{x}$ 400, eight visual fields were randomly taken using a light microscope and analyzed by Image-Pro Plus (version 4.1; Media Cybernetics, Inc.), and their mean density was measured. The mean value was taken to represent the level of protein expression.

Western blot analysis. Total proteins from frozen liver tissue specimens and/or HSC-T6 cells were extracted with RIPA lysis buffer (Beyotime Institute of Biotechnology) according to the manufacturer's protocol. The Bradford assay was used to determine the protein concentration of samples. Then, equal amounts $(8 \mu \mathrm{g})$ of each protein sample was separated on $10 \%$ SDS-PAGE, transferred onto PVDF membranes that were then blocked with $5 \%$ skimmed milk at room temperature for $1 \mathrm{~h}$. After blocking, the membranes were incubated overnight at $4{ }^{\circ} \mathrm{C}$ with primary antibodies, followed by incubation with horseradish peroxidase-conjugated goat anti-rabbit secondary antibody (1:5,000; cat. no. 7074; Cell Signaling Technology, Inc.) at $37^{\circ} \mathrm{C}$ for $45 \mathrm{~min}$. Primary antibodies included rabbit anti-GAPDH $(1: 1,000$; cat. no. 5174; Cell Signaling Technology, Inc.), rabbit antiNrf2 (1:3,000; cat. no. ab137550), rabbit anti-HO-1 (1:2,000; cat. no. ab13243) both from Abcam, rabbit anti-p-Smad2C $(1: 1,000$; cat. no. 18338) and rabbit anti-p-Smad2C (1:1,000; cat. no. 3104) both from Cell Signaling Technology, Inc. Then, the proteins bands were visualized with the ECL chemiluminescence system (GE Healthcare). The density of each protein blot was compared with that of GAPDH using ImageJ software (version 1.46r; National Institutes of Health) and was shown as a ratio to the endogenous control. These experiments were repeated three times.

Statistical analysis. Data are presented as the mean \pm SD, $\mathrm{n}=6$. Statistical analysis were performed using SPSS 22 (IBM Corp.). Differences between groups were compared using ANOVA followed by Tukey's post hoc test. Data represent $\geq 3$ independent experiments. $\mathrm{P}<0.05$ was considered to indicate a statistically significant difference.

\section{Results}

Effect of Sal B on acute and chronic liver injury. In acute liver injury, it was found that hepatocytes in the $\mathrm{CCl}_{4}$ model group were irregular with obvious pathological changes, such as necrosis and inflammatory cell infiltration (Fig. 1A). When treated with Sal B, pathological changes in the model group were significantly improved in a concentration-dependent manner. In chronic liver injury experiment, hepatocytes in the $\mathrm{CCl}_{4}$ model group were necrotic with liver fibrosis seen in the intercellular and portal area of hepatocytes (Fig. 1B). In contrast, the degree of liver fibrosis in the Sal B groups showed a dose-dependent reduction in liver injury. The present study also measured ALT and AST levels in mouse serum. In acute liver injury, $\mathrm{CCl}_{4}$ significantly increased ALT and AST levels compared with the control group, while Sal B significantly decreased these factors in concentration-dependent manner compared with the model group (Fig. 2A). In the chronic liver injury model, Sal B significantly decreased ALT and AST levels compared with the model group (Fig. 2B).

Effects of Sal B on antioxidant enzymes in acute and chronic liver injury. In the acute liver injury experiment, MDA, a byproduct of lipid peroxidation, was significantly increased after $\mathrm{CCl}_{4}$ treatment, while the addition of Sal B resulted in a concentration-dependent decrease in MDA production (Fig. 3A). In contrast, antioxidants such as SOD and GSH were increased in response to Sal B treatment, particularly in the Sal B $30 \mathrm{mg} / \mathrm{kg}$ group. These results were consistent with those found in the chronic liver injury model, as indicated in Fig. 3B. 

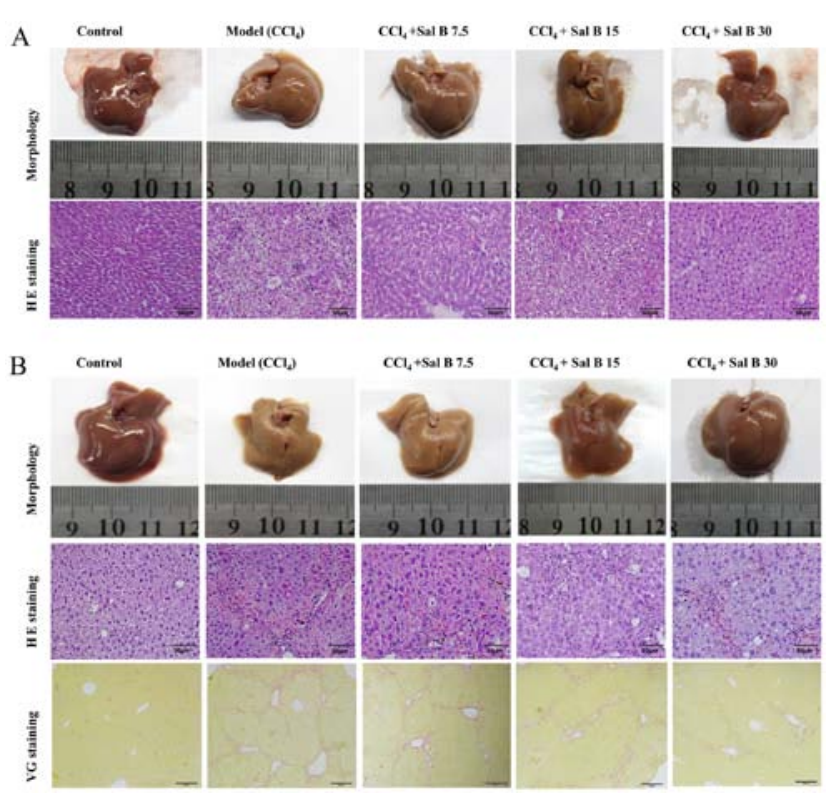

Figure 1. Effects of Sal B on pathological changes in $\mathrm{CCl}_{4}$-induced acute and chronic liver injury by $\mathrm{HE}$ and VG staining. Representative liver sections from (A) acute liver injury and (B) chronic liver injury. $n=6$ mice per group. These representative figures were randomly selected from each group. Magnification, $\mathrm{x} 400$ in HE staining and x100 in VG staining. Scale bar, $50 \mu \mathrm{m}$. HE, hematoxylin and eosin; VG, Van Gieson's; Sal B, salvianolic acid B.
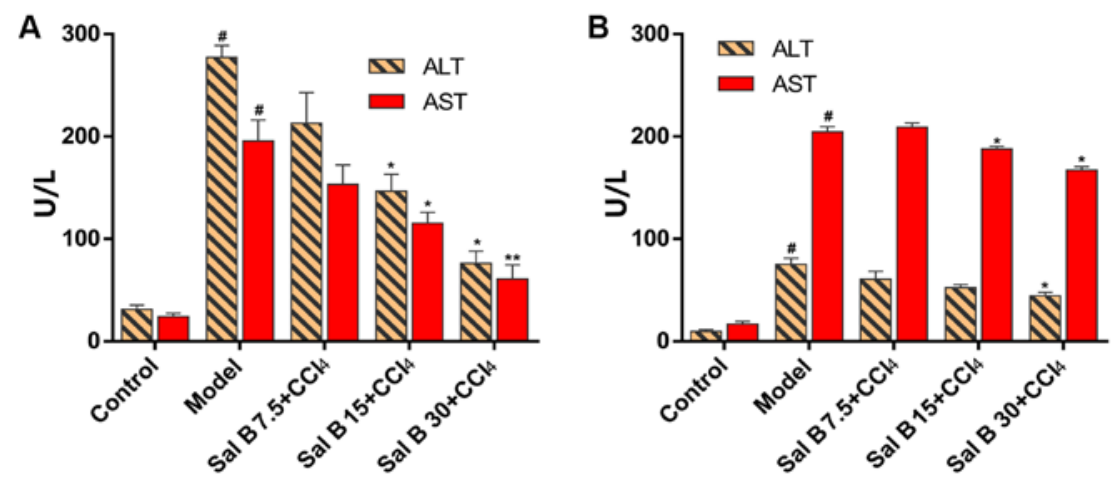

Figure 2. Effects of Sal B on changes of ALT and AST in $\mathrm{CCl}_{4}$-induced acute and chronic liver injury mice. Levels of ALT and AST in (A) acute liver injury and (B) chronic liver injury. The data were obtained from three independent experiments and presented as the mean $\pm \mathrm{SD}$. $\mathrm{n}=6$. ${ }^{*} \mathrm{P}<0.05$; ${ }^{* * *} \mathrm{P}<0.01$ vs. model group; ${ }^{\#} \mathrm{P}<0.05$ vs. control group. Sal B, salvianolic acid B; ALT, alanine transaminase; AST, aspartate aminotransferase.
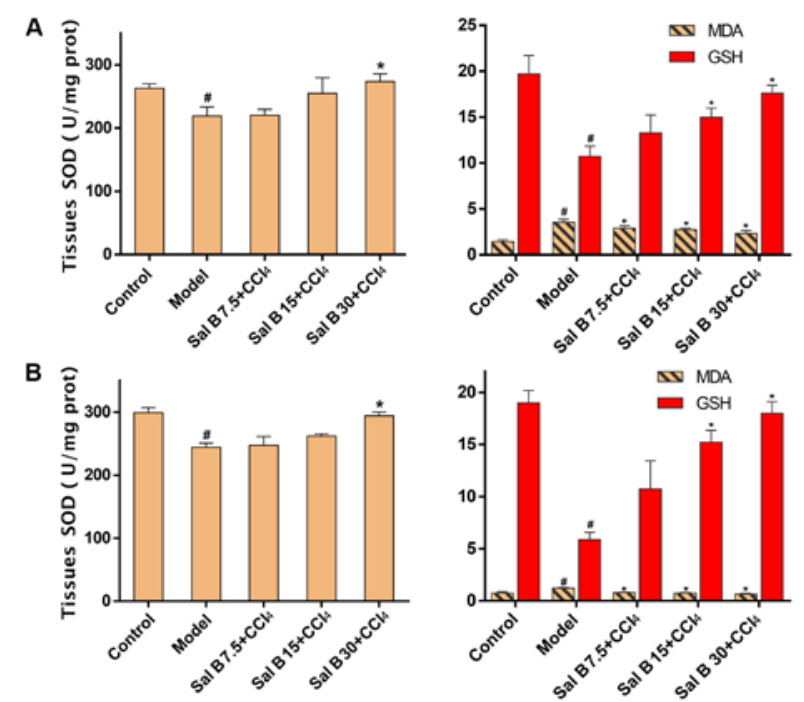

Figure 3. Effects of Sal B on the activities of antioxidant enzymes in $\mathrm{CCl}_{4}$-induced acute and chronic liver injury. Levels of SOD, MDA and GSH in (A) acute liver injury and (B) chronic liver injury. The data were obtained from three independent experiments and presented as the mean $\pm \mathrm{SD}$. $\mathrm{n}=6 .{ }^{*} \mathrm{P}<0.05$ vs. model group; ${ }^{\#} \mathrm{P}<0.05$ vs. control group. Sal B, salvianolic acid B; SOD, superoxide dismutase; MDA, malondialdehyde; GSH, glutathione. 
A
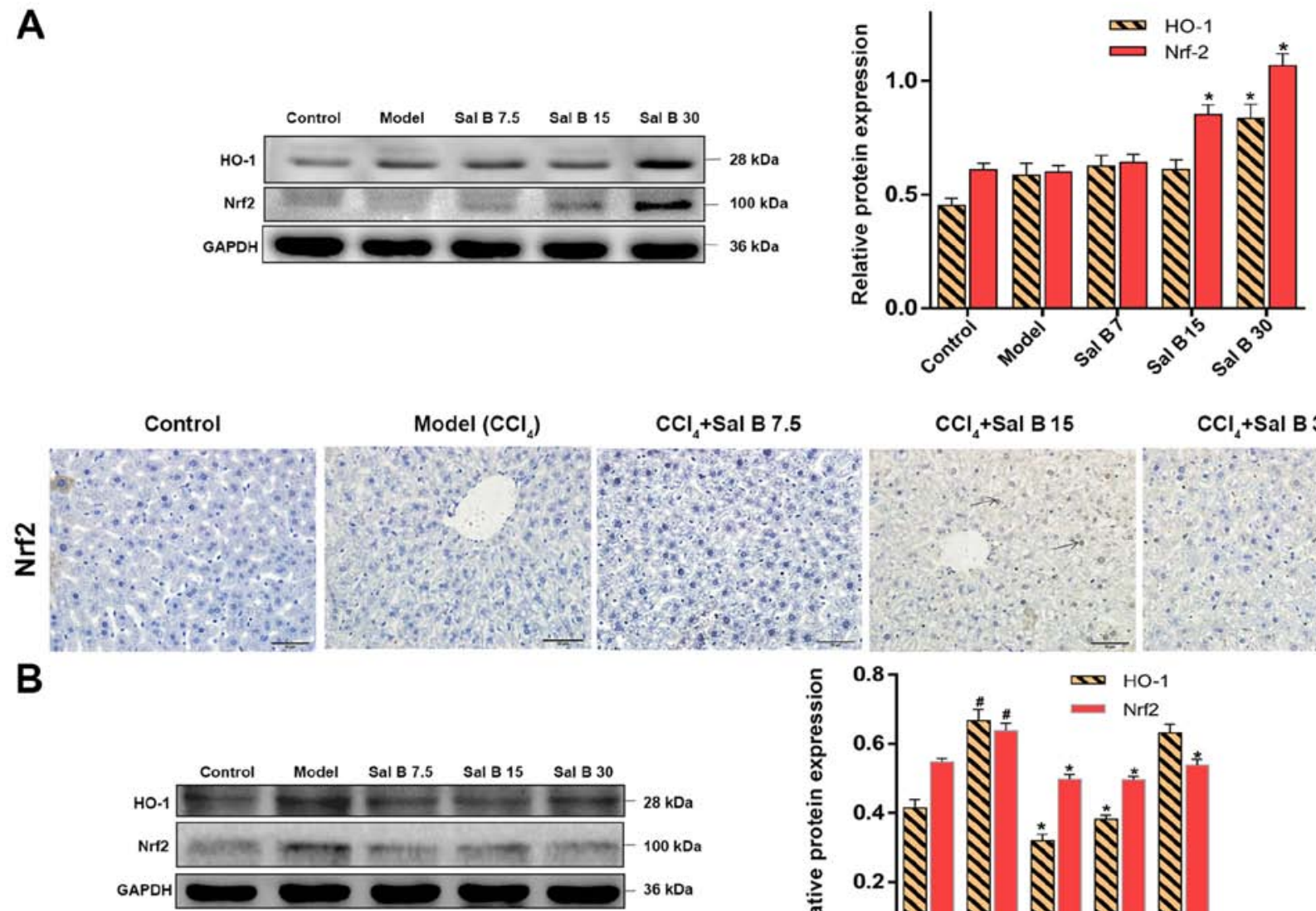

$\mathrm{Cl}_{4}+\mathrm{Sal} \mathrm{B} 7.5$

$\mathrm{CCl}_{4}+\mathrm{Sal} \mathrm{B} 15$

$\mathrm{CCl}_{4}+\mathrm{Sal} \mathrm{B} 30$

B
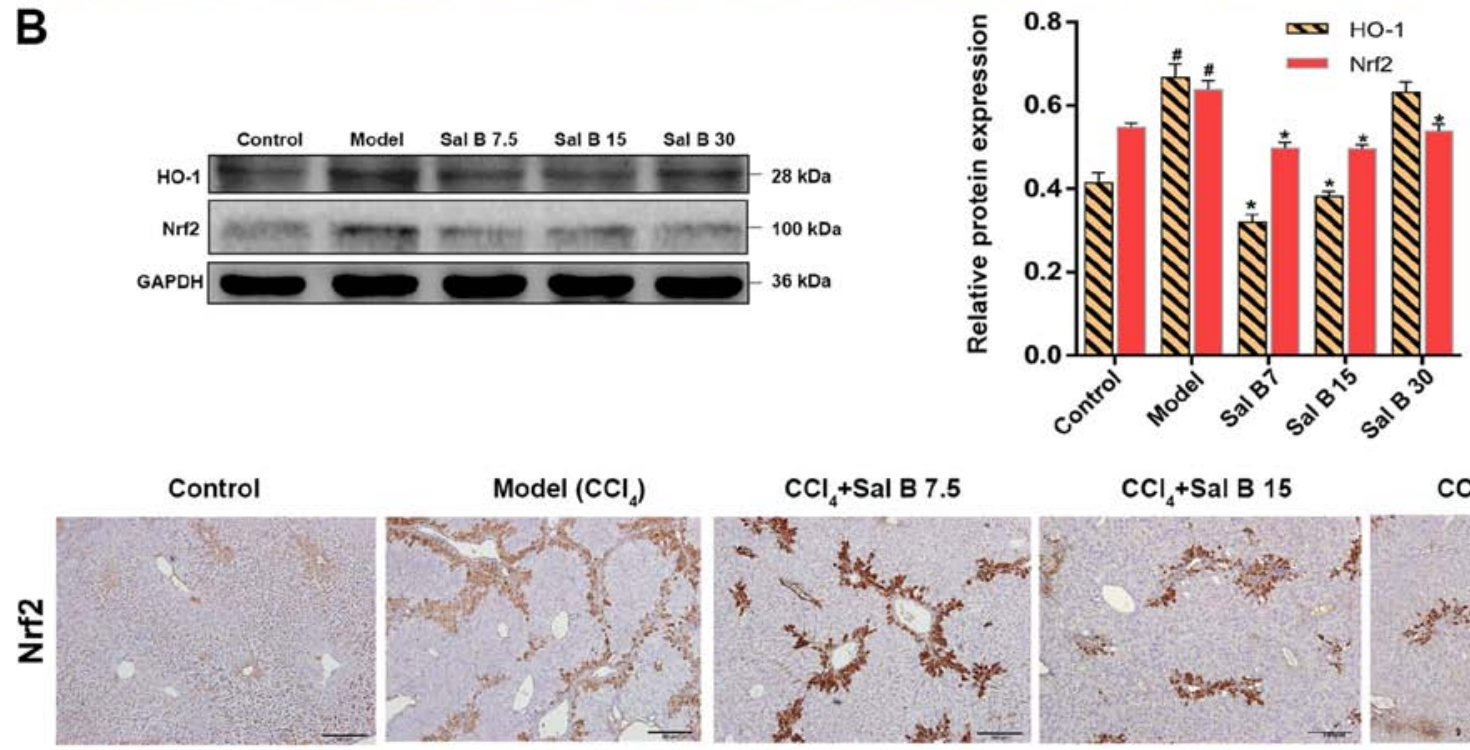

$\mathrm{CCl}+\mathrm{Sal} \mathrm{B} 30$

Figure 4. Effects of Sal B on the Nrf2/HO-1 signaling pathway in $\mathrm{CCl}_{4}$-induced acute and chronic liver injury mice. Protein expression levels of Nrf-2 and $\mathrm{HO}-1$ and immunohistochemical staining of Nrf2 were evaluated in $\mathrm{CCl}_{4}$-induced (A) acute injury and (B) chronic liver injury. Samples were derived from the same experiment and the blots were processed in parallel, all the experiments were repeated $\geq 3$ times. Data are presented as the mean $\pm S D$. $n=6$. " $P<0.05$ vs. model group; ${ }^{*} \mathrm{P}<0.05$ vs. control group. Sal B, salvianolic acid B; HO-1, heme oxygenase-1; Nrf2, nuclear factor erythroid-2-related factor 2.

Effects of Sal B on the Nrf2/HO-1 signaling pathway. The kelch like ECH associated protein 1/Nrf2/HO-1 signaling pathway plays an important role in the process of antioxidative damage and inflammatory injury of cells (22). The protein expression levels of $\mathrm{Nrf} 2$ and $\mathrm{HO}-1$ were upregulated by $\mathrm{CCl}_{4}$ treatment, and were further increased after the addition of $30 \mathrm{mg} / \mathrm{kg} \mathrm{Sal}$ $\mathrm{B}$ in acute liver injury mice (Fig. 4A). However, in chronic liver injury mice Nrf2 and HO-1 were downregulated compared with the model group (Fig. 4B). Moreover, immunohistochemistry showed that activated $\mathrm{Nrf} 2$ was present around the central vein in $\mathrm{CCl}_{4}$, Sal B 7.5, Sal B 15 and Sal B 15 groups. It was found that liver fibrosis in the Sal B-treated groups was improved and the area of Nrf2 expression was decreased (Fig. 4B). Additionally, the present results suggested that Sal B regulates the Nrf2 signal more strongly in acute liver injury compared with chronic liver injury.
Effects of Sal B on pSmad2C/L in acute and chronic liver injury mice. To assess whether Sal B could affect the phosphorylation of Smad2C and Smad2L, acute and chronic liver injury mice were treated with different doses of Sal B. It was found that the protein expression levels of $\mathrm{pSmad} 2 \mathrm{C}$ and $\mathrm{pSmad} 2 \mathrm{~L}$ were decreased after Sal B treatment (Fig. 5A). Furthermore, this downregulation in pSmad2C and $\mathrm{pSmad} 2 \mathrm{~L}$ was more distinctive in chronic liver injury mice (Fig. 5B).

Effects of Sal B on the Nrf2/HO-1 signaling pathway in $\mathrm{H}_{2} \mathrm{O}_{2}$ induced HSC-T6 injury. To understand the mechanisms of the attenuation of oxidative stress by Sal B, the present study hypothesized that the antioxidant capability of Sal B may result from increased levels of Nrf2 and HO-1. In comparison with the control group, the protein expression levels of Nrf2 and HO-1 in the model group were slightly increased, but this 

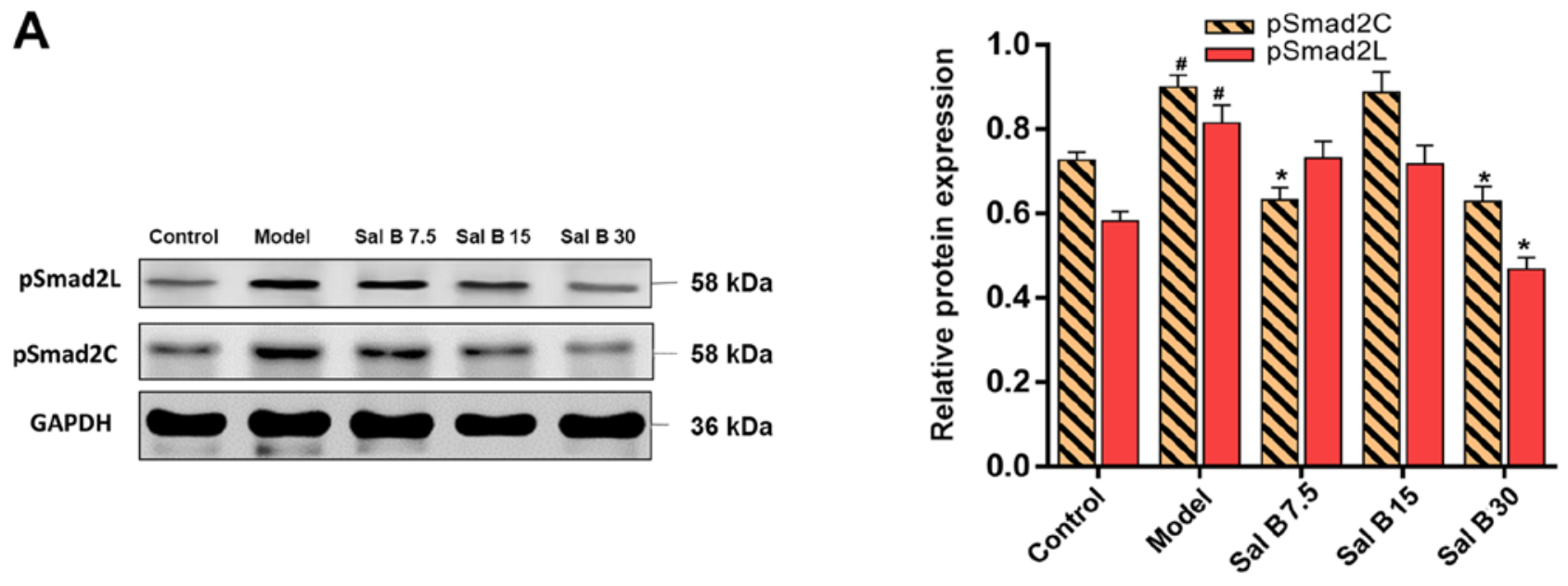

B
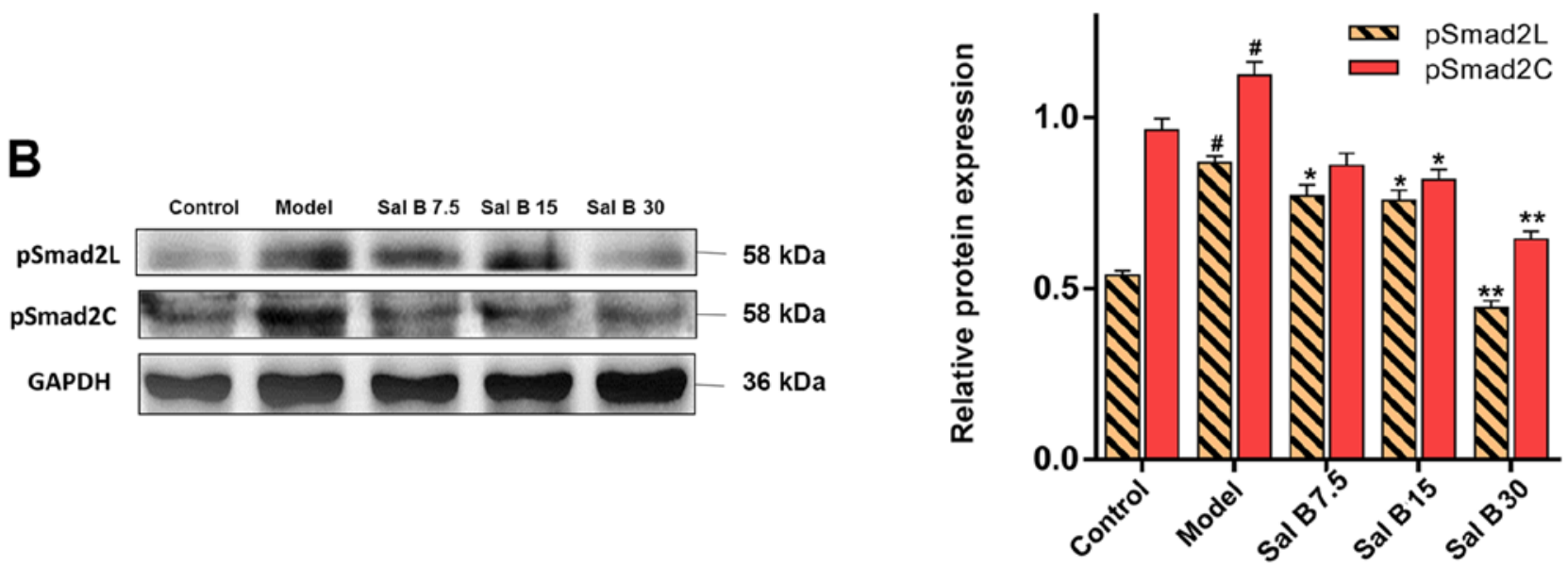

Figure 5. Effects of Sal B on pSmad2C and pSmad2L in $\mathrm{CCl}_{4}$-induced acute and chronic liver injury mice. Protein expression levels of pSmad2L and pSmad2C were evaluated in (A) $\mathrm{CCl}_{4}$-induced acute injury and (B) chronic liver injury. Samples derive from the same experiment and the blots were processed in parallel, all the experiments were repeated $\geq 3$ times. Data are presented as the mean $\pm \mathrm{SD}$. $\mathrm{n}=6 .{ }^{*} \mathrm{P}<0.05$ and ${ }^{* * *} \mathrm{P}<0.01$ vs. model group; ${ }^{*} \mathrm{P}<0.05$ vs. control group. $\mathrm{P}-$, phosphorylated; Smad2C, Smad2 at COOH-terminal; Smad2L, Smad2 at linker region.
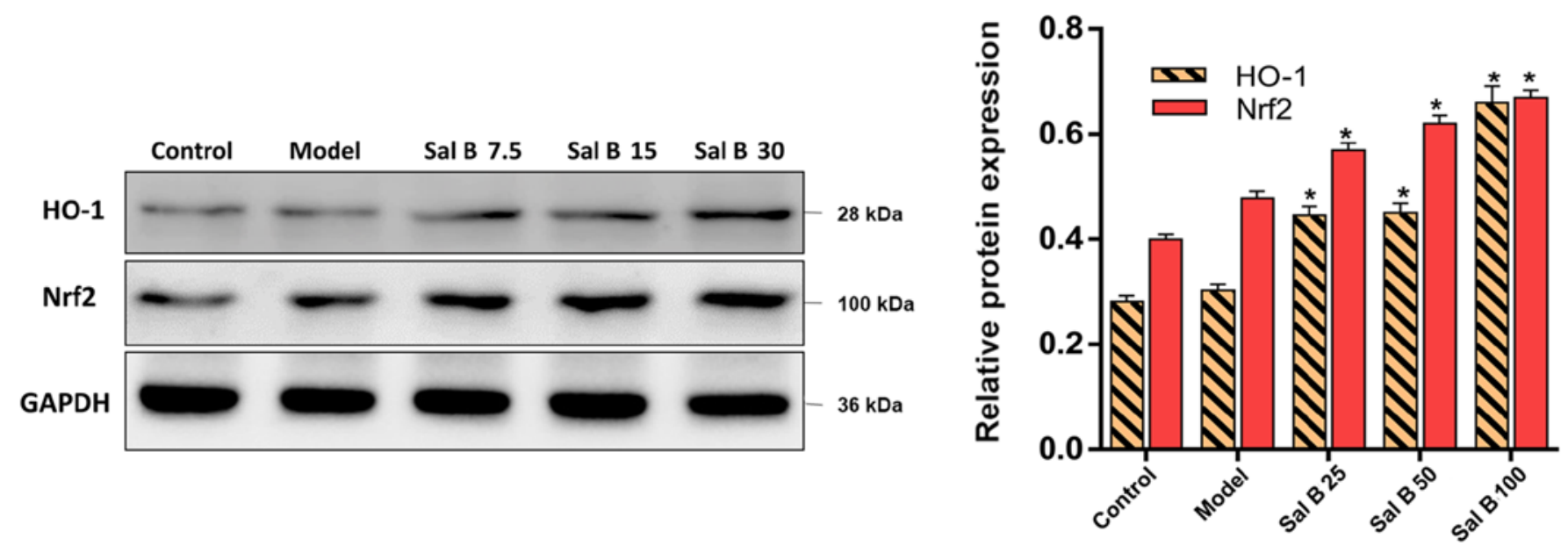

Figure 6. Effects of Sal B on Nrf2 and HO-1 in $\mathrm{H}_{2} \mathrm{O}_{2}$ induced HSC-T6 cells injury. Protein expression levels of Nrf2 and HO-1 were evaluated in $\mathrm{H}_{2} \mathrm{O}_{2}$ induced cells injury. Samples derive from the same experiment and the blots were processed in parallel, all the experiments were repeated $\geq 3$ times. Data are presented as the mean \pm SD. $n=6$. ${ }^{*} \mathrm{P}<0.05$ vs. model group. Sal B, salvianolic acid B; HO-1, heme oxygenase-1; Nrf2, nuclear factor erythroid-2-related factor 2.

was not significant (Fig. 6). However, pretreatment of HSC-T6 cells stimulated by $\mathrm{H}_{2} \mathrm{O}_{2}$ with Sal B $(25,50$ or $100 \mu \mathrm{mol} / \mathrm{l})$ showed a concentration-dependent increase in the protein expression level of Nrf2. Therefore, the in vitro data showed similar patterns to the results from the animal experiments, which suggested that the protective effect of Sal B are via the activation of the Nrf2/HO-1 signaling pathway in acute and chronic liver injury mice. 

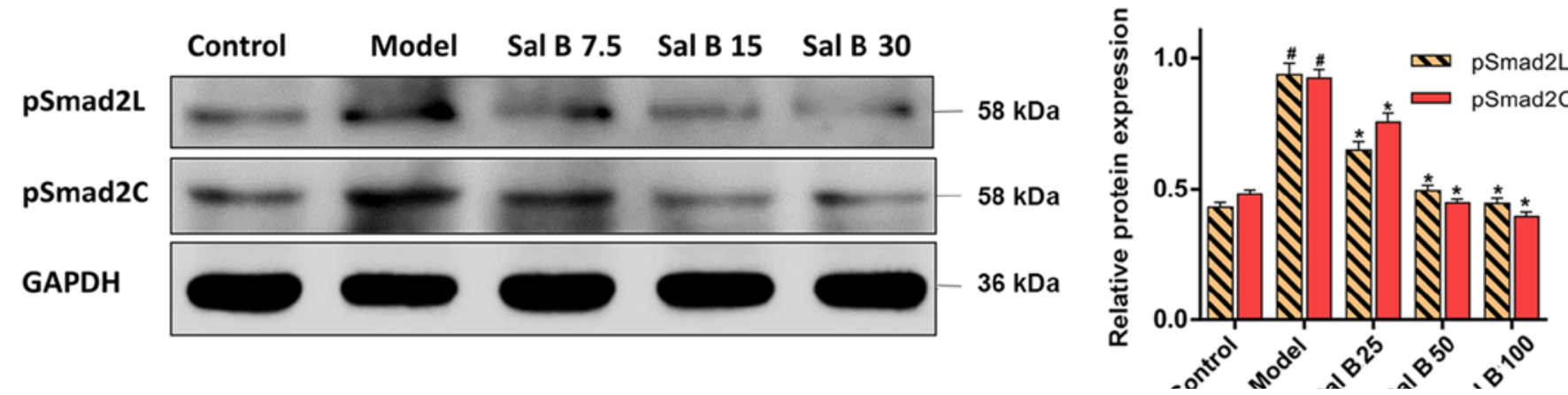

Figure 7. Effects of Sal B on pSmad2C and pSmad2 2 in $\mathrm{H}_{2} \mathrm{O}_{2}$ induced HSC-T6 cells injury. Protein expression levels of pSmad2L and pSmad2C were evaluated in $\mathrm{H}_{2} \mathrm{O}_{2}$ induced cells injury. Samples derive from the same experiment and the blots were processed in parallel, all the experiments were repeated $\geq 3$ times. Data are presented as the mean \pm SD. $\mathrm{n}=6 .{ }^{~} \mathrm{P}<0.05$ vs. model group; ${ }^{*} \mathrm{P}<0.05$ vs. control group. $\mathrm{P}-$, phosphorylated; Smad2C, Smad2 at $\mathrm{COOH}$-terminal; Smad2L, Smad2 at linker region.

Effects of Sal B on pSmad2C/L in H2O2 induced HSC-T6 injury. It was demonstrated that $\mathrm{H}_{2} \mathrm{O}_{2}$ treatment significantly increased the protein expression levels of pSmad2C and pSmad2L in the model group (Fig. 7). However, the protein expression levels of $\mathrm{pSmad} 2 \mathrm{C}$ and $\mathrm{pSmad} 2 \mathrm{~L}$ were significantly decreased by Sal B $(25,50$ and $100 \mu \mathrm{mol} / \mathrm{l})$ treatment. Collectively, the present results suggested that Sal B might have a protective effect on both acute and chronic liver injury, which involved the downregulation of pSmad2C and pSmad2L.

\section{Discussion}

Toxic reagents produce excessive electrophilic products and free radicals, which are important factors of inducing liver injury, resulting in lipid peroxidation, infiltration of inflammatory cells and necrosis $(23,24)$. Thus, these contribute to the progression of persistent liver injury to liver fibrosis (25). Currently, clinical antihepatic fibrosis methods mainly include antiviral therapy and discontinuation of drugs, which can cause liver injury (26). Therefore, understanding the underlying mechanisms of anti-acute and -chronic liver injury drugs may facilitate the clinical treatment of liver injury. An increasing number of studies have investigated the anti-hepatic injury activity of natural herbs (27-29). Clinical and experimental studies have demonstrated that some herbal extracts have preventive and therapeutic values against chronic liver diseases. Sal B is considered as one of the drugs with most potential in this herbal medicine category $(30,31)$. Another previous study suggested that Sal B exerts an antihepatic fibrosis-carcinoma effect via the mediation of pSmad3C/ pSmad3L (16). The present study investigated whether Sal B could protect $\mathrm{CCl}_{4}$ - and $\mathrm{H}_{2} \mathrm{O}_{2}$-induced acute and chronic liver injury, and the possible mechanism involved, with a focus on its effect on $\mathrm{pSmad} 2 \mathrm{C} / \mathrm{L}$ in liver injury pathogenesis.

Serum AST and ALT levels are commonly used indexes to assess the degree of hepatocyte damage. Elevation of serum AST and ALT levels contributes to liver damage as normally these factors are localized in the cytoplasm, and are released into the serum after the increase of membrane permeability (32). In the present animal experiments, Sal B reduced ALT and AST levels in acute and chronic liver injury mice, thus suggesting that Sal B may alleviate $\mathrm{CCl}_{4}$-induced hepatocyte damage in mice. With the progression of liver injury, necrosis of hepatocytes occurs and the AST/ALT value can reflect the degree of hepatocyte injury and necrosis (33). Furthermore, the mitochondria remain intact and ratio of AST/ ALT $<1.0$ can be seen in acute liver injury. With the persistence of injury factors, mitochondria are damaged and AST is released from the cytoplasm of mitochondria, as a result, the ratio of AST/ALT $>1.0$ usually found in chronic liver injury (34). The histological observations in the present study were consistent with these previous results, which indicated the protective effect of Sal B on mice against the liver injury induced by $\mathrm{CCl}_{4} ; 30 \mathrm{mg} / \mathrm{kg}$ Sal B had a strong protective effect on acute and chronic liver injury. Hepatocellular damage can be triggered by $\mathrm{CCl}_{4}$ and the CYP450 enzyme system is predominantly responsible for the metabolism of $\mathrm{CCl}_{4}$ to form free radicals (35). Highly reactive radicals generated from $\mathrm{CCl}_{4}$, such as trichloromethyl and trichloromethyl peroxyl, which destroy the respiratory chain on the mitochondrial membrane (36), then accumulate ROS in the cells to produce oxidative stress (37). SOD, GSH and MDA are representative oxidative biochemical parameters (38). To determine oxidant stress, these parameters were measured in liver tissues in the present study. It was found that treatment of Sal B increased the production of GSH and SOD, while it decreased of MDA in liver tissues, which demonstrates the amelioratory effects of Sal B in oxidative stress and damage in acute and chronic liver injury. Moreover, TGF- $\beta 1$ increases intracellular ROS and inhibits antioxidant enzymes degrading, which leads to redox imbalance; in return, ROS also activates TGF- $\beta 1$, mediating a profibrogenic effect; thus, a vicious cycle forms (39). Sustained activation of TGF- $\beta /$ Smads signaling pathways may promote chronic liver injury progression to liver fibrosis $(40,41)$.

Upon activation by TGF- $\beta 1, \operatorname{Smad} 2$ and $\operatorname{Smad} 3$ are activated by $\mathrm{C}$-terminal receptor-mediated phosphorylation and oligomerized with Smad4 to form a complex, which preferentially relocates into the nucleus (42). Previous studies have shown that TGF- $\beta 1$ and pro-inflammatory cytokines synergistically promote collagen synthesis and accelerate liver fibrosis by activating HSCs and promoting the profibrogenic $\mathrm{pSmad} 2 \mathrm{C} / \mathrm{L}$ signaling pathway $(8,43)$. To investigate whether Sal B could affect profibrogenic pSmad2C/L signaling, phosphorylated Smad2C and Smad2L were detected in liver injury tissues. The present results suggested that Sal B inhibited the 
phosphorylation of Smad2C/L in a dose-dependent manner in $\mathrm{CCl}_{4}$ induced acute and chronic liver injury, especially in chronic liver injury. Therefore, the present results indicated that the anti-injury effect of Sal B inhibited phosphorylation of Smad2C and Smad2L via the canonical TGF- $\beta / S m a d$ signaling pathway.

The Nrf2/HO-1 signaling pathway is also of importance as the activation of this pathway enhances the expression of antioxidant protective genes, which has a positive effect in oxidative stress (44). Previous studies have identified a crosstalk between both pathways of Nrf2 and TGF- $\beta 1(45,46)$. TGF- $\beta 1$ has been demonstrated to suppress Nrf2-dependent antioxidant enzymes and TGF- $\beta /$ Smad signaling induces ATF3, which in turn complexes with Nrf2, and then the ATF3/Nrf2 complex binds with ARE to suppress Nrf2 target gene expression. Moreover, Nrf2 inhibits the TGF- $\beta /$ Smad signaling pathway by inhibiting TGF- $\beta 1$ and blocking Smad3 activation $(10,12)$. The present study found that Sal B significantly increased the total Nrf2 expression level in acute liver injury $(47,48)$, which was in line with a previous study on high-fat diet induced inflammatory function disorder (49). However, in the chronic liver injury experiment, the Nrf2 expression levels in Sal B-treatment groups were decreased. Moreover, it was demonstrated that $\mathrm{Nrf} 2$ expression was mainly localized in the HSCs, which were around the fibrotic areas. This results is consistent with results from a previous study that showed that HSCs can be activated by Nrf2 in liver tissues (50). Therefore, the decrease in Nrf2 may due to reduction of fibrosis area. Additionally, the present results suggested that Sal B significantly decreased Nrf2 expression levels in $\mathrm{H}_{2} \mathrm{O}_{2}$-induced cell injury model, which was in line with a previous study (50), and also found in the in vivo experiments where Nrf2 expression levels were not significantly different between the control and model groups. Collectively, the present results suggested that Sal B could upregulate the expression levels of Nrf2 and HO-1, and restore the oxidant/ antioxidant balance. Thus, the activation of the Nrf2/HO-1 pathway could inhibit the action of the TGF- $\beta /$ Smad signaling pathway.

In conclusion, the present results suggested that Sal B protected the liver against acute and chronic injury by inhibiting phosphorylation of Smad2 both at C-terminal and link region via the TGF- $\beta /$ Smad signaling pathway. Furthermore, it was found that the Nrf2/HO-1 pathway might play an auxiliary role in this process (Fig S1).

\section{Acknowledgements}

Not applicable.

\section{Funding}

This study was supported by the National Natural Science Foundation of China (grant nos. 81573652 and 81874354).

\section{Availability of data and materials}

The datasets used and/or analyzed during the current study are available from the corresponding author on reasonable request.

\section{Authors' contributions}

YY designed, initiated and directed this study. XMT, DL, CZ, GHW, CW, YYX, YK, WPL and HYD performed the experiments. XT and CW wrote the manuscript. YY revised the manuscript. All authors read and approved the final manuscript.

\section{Ethics approval and consent to participate}

All the experiments were conducted in accordance with the guidelines for ethical review of laboratory animal welfare in the Animal Center of Anhui Medical University. The animal experiments were approved by the Experimental Animal Ethics Committee of Anhui Medical University.

\section{Patient consent for publication}

Not applicable.

\section{Competing interests}

The authors declare that they have no competing interests.

\section{References}

1. Ramadori G, Moriconi F, Malik I and Dudas J: Physiology and pathophysiology of liver inflammation, damage and repair. J Physiol Pharmacol 59: 107-117, 2008.

2. Hernandez-Gea V and Friedman SL: Pathogenesis of liver fibrosis. Annu Rev Pathol 6: 425-456, 2011.

3. Enomoto M, Morikawa H, Tamori A and Kawada N: Noninvasive assessment of liver fibrosis in patients with chronic hepatitis B. World J Gastroenterol 20: 12031-12038, 2014.

4. Dewidar B, Meyer C, Dooley S and Meindl-Beinker AN: TGF- $\beta$ in hepatic stellate cell activation and liver fibrogenesis-Updated 2019. Cells 8: 8, 2019.

5. Xu F, Liu C, Zhou D and Zhang L: TGF- $\beta /$ SMAD pathway and its regulation in hepatic fibrosis. J Histochem Cytochem 64: 157-167, 2016.

6. Yoshida K, Murata M, Yamaguchi T, Matsuzaki K and Okazaki $\mathrm{K}$ : Reversible human TGF- $\beta$ signal shifting between tumor suppression and fibro-carcinogenesis: Implications of Smad phospho-isoforms for hepatic epithelial-mesenchymal transitions. J Clin Med 5: 5, 2016.

7. Yoshida K, Murata M, Yamaguchi T and Matsuzaki K: TGF- $\beta$ / Smad signaling during hepatic fibro-carcinogenesis (review). Int J Oncol 45: 1363-1371, 2014.

8. Matsuzaki K: Smad phosphoisoform signals in acute and chronic liver injury: Similarities and differences between epithelial and mesenchymal cells. Cell Tissue Res 347: 225-243, 2012.

9. Arfmann-Knübel S, Struck B, Genrich G, Helm O, Sipos B, Sebens $S$ and Schäfer $H$ : The crosstalk between Nrf2 and TGF- $\beta 1$ in the epithelial-mesenchymal transition of pancreatic duct epithelial cells. PLoS One 10: e0132978, 2015.

10. Choi HK, Pokharel YR, Lim SC, Han HK, Ryu CS, Kim SK, Kwak MK and Kang KW: Inhibition of liver fibrosis by solubilized coenzyme Q10: Role of Nrf2 activation in inhibiting transforming growth factor-betal expression. Toxicol Appl Pharmacol 240: 377-384, 2009.

11. Okita Y, Kamoshida A, Suzuki H, Itoh K, Motohashi H, Igarashi K, Yamamoto M, Ogami T, Koinuma D and Kato M: Transforming growth factor- $\beta$ induces transcription factors MafK and Bach1 to suppress expression of the heme oxygenase-1 gene. J Biol Chem 288: 20658-20667, 2013.

12. Michaeloudes $C$, Chang PJ, Petrou $M$ and Chung KF: Transforming growth factor- $\beta$ and nuclear factor E2-related factor 2 regulate antioxidant responses in airway smooth muscle cells: Role in asthma. Am J Respir Crit Care Med 184: 894-903, 2011.

13. Cao W, Guo XW, Zheng HZ, Li DP, Jia GB and Wang J: Current progress of research on pharmacologic actions of salvianolic acid B. Chin J Integr Med 18: 316-320, 2012. 
14. Lin YL, Wu CH, Luo MH, Huang YJ, Wang CN, Shiao MS and Huang YT: In vitro protective effects of salvianolic acid $\mathrm{B}$ on primary hepatocytes and hepatic stellate cells. J Ethnopharmacol 105: 215-222, 2006.

15. Tao YY, Wang QL, Shen L, Fu WW and Liu CH: Salvianolic acid $B$ inhibits hepatic stellate cell activation through transforming growth factor beta-1 signal transduction pathway in vivo and in vitro. Exp Biol Med (Maywood) 238: 1284-1296, 2013.

16. Ying M, Meng F, Chao W, et al: Salvianolic acid B exerts antihepatic fibrosis-carcinoma effect via mediation of pSmad3C/ pSmad3L. Zhongguo Yaolixue Tongbao 1: 44-50, 2018.

17. Jiang W, Gao M, Sun S, Bi A, Xin Y, Han X, Wang L, Yin Z and Luo L: Protective effect of L-theanine on carbon tetrachlorideinduced acute liver injury in mice. Biochem Biophys Res Commun 422: 344-350, 2012.

18. Chu X, Wang H, Jiang YM, Zhang YY, Bao YF, Zhang X, Zhang JP, Guo H, Yang F, Luan YC, et al: Ameliorative effects of tannic acid on carbon tetrachloride-induced liver fibrosis in vivo and in vitro. J Pharmacol Sci 130: 15-23, 2016.

19. El-Wakeel SA, Rahmo RM and El-Abhar HS: Anti-fibrotic impact of Carvedilol in a CCl-4 model of liver fibrosis via serum microRNA-200a/SMAD7 enhancement to bridle TGF- $\beta 1 /$ EMT track. Sci Rep 8: 14327, 2018.

20. Al-Saeedi FJ: Study of the cytotoxicity of asiaticoside on rats and tumour cells. BMC Cancer 14: 220, 2014

21. Hu X, Liang Y, Zhao B and Wang Y: Oxyresveratrol protects human lens epithelial cells against hydrogen peroxide-induced oxidative stress and apoptosis by activation of Akt/HO-1 pathway. J Pharmacol Sci 139: 166-173, 2019

22. Loboda A, Damulewicz M, Pyza E, Jozkowicz A and Dulak J: Role of Nrf2/HO-1 system in development, oxidative stress response and diseases: An evolutionarily conserved mechanism. Cell Mol Life Sci 73: 3221-3247, 2016.

23. Morita M, Ishida N, Uchiyama K, Yamaguchi K, Itoh Y, Shichiri M, Yoshida Y, Hagihara Y, Naito Y, Yoshikawa T, et al: Fatty liver induced by free radicals and lipid peroxidation. Free Radic Res 46: 758-765, 2012.

24. Patel SJ, Milwid JM, King KR, Bohr S, Iracheta-Vellve A, Li M, Vitalo A, Parekkadan B, Jindal R and Yarmush ML: Gap junction inhibition prevents drug-induced liver toxicity and fulminant hepatic failure. Nat Biotechnol 30: 179-183, 2012.

25. Tsukamoto H, French SW, Benson N, Delgado G, Rao GA, Larkin EC and Largman C: Severe and progressive steatosis and focal necrosis in rat liver induced by continuous intragastric infusion of ethanol and low fat diet. Hepatology 5: 224-232, 1985.

26. Schuppan D: Liver fibrosis: Common mechanisms and antifibrotic therapies. Clin Res Hepatol Gastroenterol 39: 51-59, 2015.

27. Chen SR, Chen XP, Lu JJ, Wang Y and Wang YT: Potent natural products and herbal medicines for treating liver fibrosis. Chin Med 10: 7, 2015.

28. Stickel F and Schuppan D: Herbal medicine in the treatment of liver diseases. Dig Liver Dis 39: 293-304, 2007.

29. Ma X, Peng JH and Hu YY: Chinese Herbal Medicine-induced liver injury. J Clin Transl Hepatol 2: 170-175, 2014.

30. Rui W, Xie L, Liu X, He S, Wu C, Zhang X, Zhang L and Yang Y: Compound Astragalus and Salvia miltiorrhiza extract suppresses hepatocellular carcinoma progression by inhibiting fibrosis and PAI-1 mRNA transcription. J Ethnopharmacol 151: 198-209, 2014

31. Liu T, Xia Y, Li J, Li S, Feng J, Wu L, Zhang R, Xu S, Cheng K, Zhou Y, et al: Shikonin attenuates Concanavalin A-induced acute liver injury in mice via inhibition of the JNK pathway. Mediators Inflamm 2016: 2748367, 2016.

32. Clark JM, Brancati FL and Diehl AM: The prevalence and etiology of elevated aminotransferase levels in the United States. Am J Gastroenterol 98: 960-967, 2003.

33. Anderson FH, Zeng L, Rock NR and Yoshida EM: An assessment of the clinical utility of serum ALT and AST in chronic hepatitis C. Hepatol Res 18: 63-71, 2000.
34. Giannini E, Botta F, Fasoli A, Ceppa P, Risso D, Lantieri PB, Celle $G$ and Testa R: Progressive liver functional impairment is associated with an increase in AST/ALT ratio. Dig Dis Sci 44: 1249-1253, 1999

35. Bhadauria M, Nirala SK, Shrivastava S, Sharma A, Johri S, Chandan BK, Singh B, Saxena AK and Shukla S: Emodin reverses $\mathrm{CCl}$ induced hepatic cytochrome $\mathrm{P} 450$ (CYP) enzymatic and ultrastructural changes: The in vivo evidence. Hepatol Res 39: 290-300, 2009.

36. Comporti M: Three models of free radical-induced cell injury. Chem Biol Interact 72: 1-56, 1989.

37. Sies H: Oxidative stress: A concept in redox biology and medicine. Redox Biol 4: 180-183, 2015.

38. Kalpravidh RW, Siritanaratkul N, Insain P, Charoensakdi R, Panichkul N, Hatairaktham S, Srichairatanakool S, Phisalaphong C, Rachmilewitz E and Fucharoen S: Improvement in oxidative stress and antioxidant parameters in betathalassemia/Hb E patients treated with curcuminoids. Clin Biochem 43: 424-429, 2010.

39. Liu RM and Desai LP: Reciprocal regulation of TGF- $\beta$ and reactive oxygen species: A perverse cycle for fibrosis. Redox Biol 6: 565-577, 2015.

40. Derynck R and Zhang YE: Smad-dependent and Smad-inde pendent pathways in TGF-beta family signalling. Nature 425: 577-584, 2003

41. Inagaki Y and Okazaki I: Emerging insights into transforming growth factor beta Smad signal in hepatic fibrogenesis. Gut 56: 284-292, 2007.

42. Hu HH, Chen DQ, Wang YN, Feng YL, Cao G, Vaziri ND and Zhao YY: New insights into TGF- $\beta /$ Smad signaling in tissue fibrosis. Chem Biol Interact 292: 76-83, 2018.

43. Burch ML, Yang SNY, Ballinger ML, Getachew R, Osman N and Little PJ: TGF-beta stimulates biglycan synthesis via p38 and ERK phosphorylation of the linker region of Smad2. Cell Mol Life Sci 67: 2077-2090, 2010.

44. Zhang H, Liu YY, Jiang Q, Li KR, Zhao YX, Cao C and Yao J: Salvianolic acid A protects RPE cells against oxidative stress through activation of Nrf2/HO-1 signaling. Free Radic Biol Med 69: 219-228, 2014.

45. Oh CJ, Kim JY, Min AK, Park KG, Harris RA, Kim HJ and Lee IK: Sulforaphane attenuates hepatic fibrosis via NF-E2related factor 2-mediated inhibition of transforming growth factor- $\beta /$ Smad signaling. Free Radic Biol Med 52: 671-682, 2012.

46. Chen Q, Zhang H, Cao Y, Li Y, Sun S, Zhang J and Zhang G: Schisandrin $\mathrm{B}$ attenuates $\mathrm{CCl}_{4}$-induced liver fibrosis in rats by regulation of Nrf2-ARE and TGF- $\beta /$ Smad signaling pathways. Drug Des Devel Ther 11: 2179-2191, 2017.

47. Zhang X, Wu Q, Lu Y, Wan J, Dai H, Zhou X, Lv S, Chen X, Zhang X, Hang C, et al: Cerebroprotection by salvianolic acid B after experimental subarachnoid hemorrhage occurs via Nrf2and SIRT1-dependent pathways. Free Radic Biol Med 124 504-516, 2018.

48. Liu M, Xu H, Zhang L, Zhang C, Yang L, Ma E, Liu L and Li Y: Salvianolic acid B inhibits myofibroblast transdifferentiation in experimental pulmonary fibrosis via the up-regulation of $\mathrm{Nrf2}$. Biochem Biophys Res Commun 495: 325-331, 2018.

49. Wang B, Sun J, Shi Y and Le G: Salvianolic acid B inhibits high-fat diet-induced inflammation by activating the Nrf2 pathway. J Food Sci 82: 1953-1960, 2017.

50. Lu C, Xu W and Zheng S: Nrf2 activation is required for curcumin to induce lipocyte phenotype in hepatic stellate cells. Biomed Pharmacother 95: 1-10, 2017.

This work is licensed under a Creative Commons Attribution-NonCommercial-NoDerivatives 4.0 International (CC BY-NC-ND 4.0) License. 